\title{
Longitudinal Course of Suicidal Ideation and Predictors of its Persistence - A NESDA Study
}

Liia Kivelä ${ }^{1}$, Annegret Krause-Utz ${ }^{1}$, Joanne Mouthaan ${ }^{1}$, Maartje Schoorl ${ }^{1}$, Rianne de Kleine ${ }^{1}$, Bernet Elzinga $^{1}$, Merijn Eikelenboom ${ }^{2}$, Brenda WJH Penninx ${ }^{2}$, Willem van der Does ${ }^{1 *}, \&$ Niki Antypa ${ }^{1 *}$

${ }^{1}$ Department of Clinical Psychology, Institute of Psychology, Leiden University, The Netherlands

${ }^{2}$ Department of Psychiatry, Amsterdam Public Health Research Institute, Amsterdam UMC, Vrije

*Corresponding Authors:

Niki Antypa, PhD (nantypa@fssw.leidenuniv.nl)

and Willem van der Does, PhD (vanderdoes@,fsw.leidenuniv.nl)

Department of Clinical Psychology

Leiden University

Wassenaarseweg 52

2333AK Leiden

The Netherlands 


\begin{abstract}
BACKGROUND: Prior research indicates that the factors that trigger suicidal ideation may differ from those that maintain it, but studies into the maintenance of suicidal ideation remain scarce. Our aim was to assess the longitudinal course of suicidal ideation, and to identify predictors of persistent suicidal ideation. METHODS: We used data from the Netherlands Study of Depression and Anxiety (NESDA). We performed a linear mixed-effects growth model analysis ( $\mathrm{n}=230$ with current suicidal ideation at baseline) to assess the course of suicidal ideation over time (baseline through 2-, 4-, 6- and 9-year follow-up). We used logistic regression analysis $(n=195)$ to test whether factors previously associated with the incidence of suicidal ideation in the literature (insomnia, hopelessness, loneliness, borderline personality traits, childhood trauma, negative life events) also predict persistence of suicidal ideation (i.e., reporting ideation at two consecutive assessment points, 6- and 9-years). We controlled for socio-demographics, clinical diagnosis and severity, medication use, and suicide attempt history. RESULTS: Suicidal ideation decreased over time, and this decrease became slower with increasing time, with the majority of symptom reductions occurring in the first two years of follow-up. More severe insomnia and hopelessness were associated with increased odds of persistent suicidal ideation, and hopelessness was a significant mediator of the relationship between insomnia and persistent suicidal ideation. LIMITATIONS: Findings may not generalize to those with more severe suicidal ideation due to dropout of those with the worst clinical profile. CONCLUSIONS: Targeting insomnia and hopelessness in treatment may be particularly important to prevent the persistence of suicidal ideation.
\end{abstract}




\section{Introduction}

Suicide remains one of the most common causes of death worldwide, claiming up to 800,000 lives annually, translating to one death every 40 seconds (WHO, 2018). For every suicide death, 20 suicide attempts are estimated to occur (WHO, 2014), and almost 10\% of the general population experiences suicidal ideation at some point in their lives (Nock et al., 2008).

Suicidal ideation is known to precede and increase the risk of suicide (Nock et al., 2008; Rossom et al., 2017). Although suicidal ideation assessed at a single time point is a poor predictor of subsequent suicide attempt and mortality (Busch et al., 2003; Oquendo et al., 2006), persistent suicidal ideation markedly increases the risk of suicide (Kessler et al., 1999). In fact, 'serious' suicide attempters (i.e., those with clear intent to die) report suicidal ideation lasting weeks to months prior to attempt (Anestis et al., 2014). However, most studies rely on assessments of suicidal ideation performed at a single time point, and the persistence of suicidal thoughts remains a largely neglected topic in suicidology.

Many psychosocial factors can increase the risk of suicidal ideation and behavior. Among these, a past suicide attempt is the strongest predictor for subsequent suicide (Antypa et al., 2013; Hawton et al., 2013). Mental disorders are also a major risk factor. Over $90 \%$ of people who make a serious suicide attempt (Beautrais et al., 1996) or die from suicide have a history of a psychiatric disorder (Cavanagh et al., 2003; Henriksson et al., 1993). The diagnosis most often associated with suicide is depression (Beautrais et al., 1996; Henriksson et al., 1993; Nock et al., 2008), but anxiety disorders are closely linked due to their high comorbidity with depression (Hawton et al., 2013). Approximately 30-40\% of people with suicide mortality also have personality psychopathology (Duberstein \& Conwell, 1997; Henriksson et al., 1993). Borderline personality disorder (BPD) traits (i.e., subsyndromal BPD symptoms, such as affective instability, instable relationships and self-harming impulsivity) specifically are associated with high rates of suicide attempts (84\%) and deaths (10\%) (Black et al., 2004; Yen et al., 2004; Zimmerman et al., 2012). These and other psychopathological syndromes (e.g., schizophrenia, addictions) represent important risk factors, but they are also quite common. Compared with these large numbers, suicide remains a relatively rare event. Predicting a rare event, in this case inferring suicide risk from psychiatric status, is hence limited by the low base rate of suicide (Yufit \& Lester, 2005). Since a fatal suicide is usually preceded by long periods of continuous or intermittent suicidal ideation, it may be more fruitful to investigate the predictors of persistent suicidal ideation. Furthermore, research may benefit from consideration of additional risk factors.

Hopelessness, a vulnerability factor for depression, is central in most theoretical models 
of suicide (O'Connor \& Knock, 2014; Smith et al., 2006). Suicidal ideation and suicide have been found to be more strongly associated with hopelessness than depression (Minkoff et al., 1973; Kuo et al., 2004). In a prospective study of 207 individuals hospitalized for suicidal ideation, 'hopelessness about the future' correctly classified $91 \%$ of the individuals who subsequently died by suicide (Beck et al., 1985). Furthermore, hopelessness reactivity (i.e., the tendency to respond with hopeless cognitions to mild sadness) was higher in remitted depressed individuals with a history of suicidal ideation than in remitted depressed individuals without such history (Antypa et al., 2010).

Loneliness has also been implicated in the etiology of suicidal ideation: this includes both subjective (i.e., feeling lonely) and objective loneliness (i.e., living alone and/or lack of friends) (Stravynski \& Boyer, 2001). Among older adults, lack of social relationships was the variable most strongly associated with suicidal ideation, surpassing depressive symptoms (Almeida, 2012). However, this association was not observed in adolescents (Lasgaard et al., 2011).

More recently, insomnia, both as a symptom of depression and as an independent disturbance, has been associated with suicide (Bernert et al., 2005; McCall \& Black, 2013; Perlis et al., 2016). Sleep disturbances are reported by up to $92 \%$ of suicide attempters (Hall et al., 1999). Insomnia symptoms were also found to predict suicidal ideation and behavior independently of depressive symptoms and hopelessness in a prospective study of young adults (Ribeiro et al., 2012).

Suicide risk is also increased after exposure to stressors (WHO, 2017), particularly interpersonal conflicts or loss (Hall et al., 1999; Stroebe et al, 2005), independent of psychiatric status (Foster et al., 1999). However, some studies found no association between suicide and number or severity of current stressors (Cavanagh et al., 1999). In addition to recent stressors, childhood trauma is associated with increased suicidal ideation and behavior in both adolescents and adults (Almeida, 2012; Brodsky et al., 2001; Brown et al., 1999). In particular, emotional and sexual abuse confer increased risk (Brown et al., 1999; de Araújo \& Lara, 2016).

Suicidal ideation can be a long-term condition. In two large studies in approximately 5,000 Dutch and US adults, almost a third of participants with suicidal ideation still experienced ideation after two years (Ten Have et al., 2009) and more than a third reported persistent suicidal ideation over ten years (Borges et al., 2008). Continuous high risk was also reported in subsamples of adolescent (Goldston et al., 2016) and adult patients (Handley et al., 2013). There is limited evidence to suggest that different factors predict the onset and maintenance of suicidality. Anxiety was associated with the onset of suicidal ideation, whereas hopelessness 
with its persistence (Zhang et al., 2011). Low social support, domestic violence, and high depressive symptoms were also associated with persistence (Wilcox et al., 2010).

In summary, considerable heterogeneity exists in the course of suicidal ideation over time (Goldston et al., 2016), and approximately one third of patients report persistent ideation (Borges et al., 2008; Handley et al., 2013). Consequently, it is important to describe suicide risk not only in terms of current severity but also in terms of chronicity (Wortzel et al., 2014). However, the aforementioned studies only included two assessment time points and were limited in the range of included predictors.

The aim of the present study was to assess the course of suicidal ideation over nine years and to investigate predictors of its persistence. We used data from the Netherlands Study of Depression and Anxiety (NESDA), a large naturalistic cohort study of adults with and without depression and anxiety disorders (Penninx et al., 2008). We tested predictors previously implicated in the incidence of suicidal ideation - insomnia symptoms, hopelessness, loneliness, BPD traits, negative life events, childhood trauma - to examine how they influence (i) the course of suicidal ideation over time, and (ii) the maintenance or development of persistent suicidal ideation over time. We hypothesized that individuals with more insomnia symptoms, hopelessness, loneliness, BPD traits and recent negative life events, and more severe childhood trauma history would (i) experience more suicidal ideation; and (ii) have an increased likelihood of experiencing persistent suicidal ideation, controlling for socio-demographics, clinical diagnosis and severity, medication use, and suicide attempt history. Post-hoc mediation analyses were run for significant predictors of persistent ideation, and rationales for those were based on prior literature.

\section{Method}

\section{Participants and procedure}

Participants for the NESDA were recruited between 2004-2007 from the community and health care settings in Amsterdam, Groningen and Leiden. After a baseline assessment of socio-demographic and clinical variables (see Penninx et al., 2008 for rationale and methods), follow-up assessments were performed at 2, 4, 6, and 9 years. At baseline, the NESDA sample consisted 2,981 adults aged 18-65 years.

Course of suicidal ideation As primary inclusion criteria for the course analyses (Hypothesis 1), participants were required to have 1. available data on suicidal ideation and the predictors at baseline (or at 4-year follow-up for childhood trauma and BPD traits, which were only included later), and 2. at least one follow-up $(n=2,130)$. Out of these participants, 230 
(11\%) were categorized as 'suicidal ideators' (i.e., reported at least mild suicidal ideation at baseline, Beck Scale for Suicide Ideation (BSSI)>0), while 1,900 (89\%) were 'non-suicidal' (i.e., no suicidal ideation at baseline, BSSI=0). We further restricted our sample to those participants who were suicidal ideators at baseline $(n=230$; see Figure 1). This was done because most participants (77\%) did not report any suicidal ideation at any assessment point, and as our research question relates to the course of suicidal ideation in those already affected rather than the development of ideation in currently asymptomatic individuals.

Persistence of suicidal ideation As primary inclusion criteria for the persistence analyses (Hypothesis 2), participants were required to have available data on 1. the predictors at baseline, 2- and 4-year follow-ups, and 2. suicidal ideation at 6- and 9-year follow-ups $(n=1,663)$. We further restricted our sample to those participants who reported suicidal ideation at the 6- and/or 9-year follow-ups (i.e., excluding people with no suicidal ideation at both assessment points), as we were interested in the differences between those with persistent as compared to non-persistent suicidal ideation (assuming that reporting suicidal ideation at two successive assessment points indicates persistence). In order to assume a non-overlapping timeline, the outcome (suicidal ideation) was measured at 6- and 9-year follow-up, and the predictors and covariates were derived from baseline, 2- and 4-year follow-up (Figure 2). This allowed for a longitudinal assessment of both the outcome and predictors, therefore providing an improved measure of the predictors over time. Of the 1,663 participants with available data, 1,468 (88\%) reported no suicidal ideation at both 6 and 9 years (and were excluded), 140 (8\%) reported suicidal ideation at either 6 or 9 years (i.e., non-persistent suicidal ideation), and 55 (3\%) reported suicidal ideation at both 6 and 9 years (i.e., persistent suicidal ideation), resulting in a sample of 195 participants (Figure 1). Comparisons between samples for course analyses and persistence analyses are provided in the supplement. $32 \%(n=63)$ of the participants included in the persistence analyses were also included in the course analyses.

At baseline, participants with incomplete data (i.e., data on suicidal ideation or predictors not available) and consequently excluded from the analyses $(n=851)$ were younger $(p<.001)$, not married/no partner $(p=.023)$, had children $(p=.045)$, had fewer years of education $(p<.001)$, were unemployed $(p=.002)$, used SSRIs $(p=.004)$ and benzodiazepines $(p<.001)$, had a current diagnosis of a depressive $(p<.001)$ or anxiety disorder $(p<.001)$, comorbidity $(p<.001)$, and suicide attempt history $(p<.001)$. There were no differences between included participants and dropouts in gender, nationality, or use of other medications (all $p$ 's > .05) (in line with previously reported attrition in NESDA; Lamers et al., 2012). 
$<$ Figure $1 \&$ Figure $2>$

\section{Materials}

Sociodemographic data on participants' age, gender, nationality, marital status, education and employment were collected at baseline (Penninx et al., 2008).

Clinical diagnosis and severity, medication use (selective serotonin reuptake inhibitors (SSRIs), other antidepressants (tricyclic antidepressants, monoamine oxidase inhibitors, atypical antidepressants), benzodiazepines, hypnotics/sedatives), and suicide attempt history were assessed at baseline, and 2- and 4-year follow-up. Current and lifetime diagnoses of depressive (major depressive disorder, dysthymia) and anxiety disorders (generalized anxiety disorder, social phobia, panic disorder, agoraphobia) were assessed at baseline, and current diagnoses (i.e., past 6 months) were established again at 2- and 4-year follow-up using the Composite International Diagnostic Interview (CIDI 2.1), a DSM-IV criteria concurrent standardized diagnostic interview (Robins et al., 1988; WHO, 1998). Severity of depressive symptoms was assessed with the Inventory of Depressive Symptomatology (IDS; Rush et al., 1986; Rush et al., 1996).

Suicidal ideation was assessed at baseline and all follow-ups using a 5-item version of the Beck Scale for Suicide Ideation (BSSI), a screening measure of current (past week) suicidal ideation administered by the interviewer (Beck et al., 1979). The items are rated on a 3-point Likert-scale, and the sum score ranges from 0 to 10 (severe suicidal ideation). Respondents with a positive score on at least one of the five items of the BSSI were categorized as suicidal ideators (Kooistra et al., 2018; Lamers et al., 2016). Internal consistency of the BSSI was acceptable in our sample $(\alpha>.74)$.

Hopelessness was measured at baseline, and 2- and 4-year follow-up with the Leiden Index of Depression Sensitivity (LEIDS; van der Does, 2002) Hopelessness/Suicidal reactivity subscale (5 items). Example subscale items include: "When I feel down, I more often feel hopeless about everything" and "When I feel sad, I feel as if I care less if I lived or died" (Solis et al., 2017). Total scores range from 0 to 20 (severe hopelessness). It has been found to be a valid measure to differentiate depressed patients with and without past suicidal ideation (Antypa et al., 2010). Even though the subscale taps questions relating to suicidal ideation, these are conditional hypothetical items measuring reactivity and not actual suicidal ideation at the current moment, thereby differentiating the scale from the BSSI.

Loneliness was measured with the de Jong-Gierveld loneliness scale (de Jong-Gierveld $\&$ Kamphuis, 1985) at baseline and 2-year follow-up. The scale consists of 11 items relating to 
the subjective feeling of loneliness rated on a 3-point Likert-scale, with a total score ranging from 0 to 11 (severe loneliness).

Insomnia symptoms during the past month were assessed at baseline and 2- and 4-year follow-up with the Women's Health Initiative Insomnia Rating Scale (WHI-IRS) (Levine et al., 2003). The WHI-IRS consists of 5 items (e.g., "Did you have trouble falling asleep?") rated on a 5-point Likert-scale, with a sum score ranging from 0 to 20 (severe insomnia symptoms). Scores $\geq 9$ are indicative of clinically significant insomnia.

Borderline personality traits were assessed at the 4-year follow-up with the Personality Disorder Questionnaire (PDQ-4; Hyler et al., 1990). Ten items of the PDQ-4 correspond to DSM-IV BPD criteria. The items (e.g., "I'll go to extremes to prevent those who I love from ever leaving me") are rated by the respondent as true/false. All 'true' items produce a total score ranging from 0 to 10 . Scores $\geq 5$ are indicative of the presence of BPD.

Recent negative life events were assessed at baseline and 2- and 4-year follow-up using the Brugha List of Threatening Experiences (Brugha et al., 1985), which assesses the occurrence of 12 negative life events (incl. unemployment, violence, death and illness of close others). A total score of the number of events is produced. At baseline, events in the past year were assessed; at 2- and 4-year follow-up, the number of events since the previous interview was assessed.

Childhood trauma history was assessed at the 4-year follow-up with the Childhood Trauma Questionnaire (CTQ; Bernstein \& Fink, 1998). CTQ is a standardized self-report questionnaire with 25 items measuring the severity of five types of trauma: emotional abuse, physical abuse and sexual abuse, emotional neglect and physical neglect. Each subscale produces a score ranging from 5 (no trauma) to 25 (severe trauma).

\section{Statistical Analysis}

The data were analyzed with IBM SPSS Statistics 23.0 (SPSS Inc, Chicago, Illinois). We examined characteristics at baseline and assessed group differences between those with and without current suicidal ideation using independent samples t-tests for continuous and chisquared tests for categorical variables.

Course of suicidal ideation We performed a linear mixed-effects growth model analysis to assess the course of suicidal ideation over time (i.e., from baseline to 9-year follow-up), and to identify which predictors affected the course of suicidal ideation, controlling for the covariates (as measured at baseline; Figure 2a). We first ran six individual models with the 1) baseline sociodemographic covariates (gender, age, nationality, marital status, education, 
employment status), 2) sociodemographic covariates with time interactions, 3) baseline clinical covariates (lifetime psychopathology, current diagnosis, depressive symptom severity, comorbidity, medication, suicide attempt history), 4) clinical covariates with time interactions, 5) baseline predictors (insomnia symptoms, hopelessness, loneliness, BPD traits, childhood trauma, negative life events), and 6) predictors with time interactions. All continuous predictors were grand-mean centered by subtracting the mean from each individual observation. For the final model, we included the predictors that emerged as significant in the prior individual models. We included the covariates and predictors, time, quadratic time (i.e., acceleration/deceleration over time), and time interactions as fixed effects, and time as random effect (specifying an unstructured correlation matrix, which provides the most flexibility, does not assume constant variance across occasions and allows for dependence between measurement occasions; Daniels \& Zhao, 2003). The resulting covariance matrix, the G matrix, presents the variances of the random intercept and random slope (time), and the covariance between them (Heck et al., 2014). We performed the Benjamini-Hochberg procedure to control the false discovery rate with multiple testing (Benjamini \& Hochberg, 1995; Glickman, Rao, \& Schultz, 2014).

Persistence of suicidal ideation Logistic regression analysis was performed to see whether the predictors at Time A (i.e., at baseline and at 2- and 4-year follow-up, using the mean score of the first three assessment points) predicted persistent suicidal ideation at Time B (i.e., reporting persistent suicidal ideation at both 6- and 9-year follow-up, vs. non-persistent suicidal ideation i.e., reporting suicidal ideation at either 6- or 9-years), controlling for the covariates (as measured at Time A). Time A did not overlap with Time B in order to establish a timeline between predictors and outcome (Figure 2b). Significance was determined at $\alpha<.05$, two-sided.

Post-hoc analyses: Based on the results of the logistic regression analysis, we ran a posthoc mediation analysis to assess whether hopelessness mediated the effect of insomnia symptoms on persistent suicidal ideation (as suggested by McCall \& Black, 2013). The mediation analysis was performed using the PROCESS v2.15 macro for SPSS (Hayes, 2012; Preacher \& Hayes, 2004). The 95\% confidence interval of the indirect effect was determined by the bootstrapping procedure with 1,000 resamples (Hayes, 2012). 


\section{Results}

\section{Sample description}

Demographic information and differences between those with and without suicidal ideation at baseline are presented in Table 1. Suicidal ideators were less likely to be married or have a partner, or to be currently working; they had more lifetime and current psychopathology (diagnosis and severity), and more comorbidity (i.e., more than one current diagnosis of a depressive and/or anxiety disorder). They were also more likely to take medication, and to have a history of a suicide attempt. They had more insomnia symptoms and BPD traits, hopelessness, loneliness, and childhood trauma history. No other differences were observed (all $p$ 's $>.05$ ). Correlations between the outcome and predictors at baseline are presented in the supplement. No multicollinearity was observed.

$<$ Table 1 $>$

\section{Longitudinal course of suicidal ideation}

We first ran six preliminary models with 1) sociodemographic covariates, 2) sociodemographic covariates with time interactions, 3) clinical covariates, 4) clinical covariates with time interactions, 5) predictors, and 6) predictors with time interactions (see supplement). For the final model (Table 2), we included the factors that emerged as significant in their individual models.

There was significant interindividual variation in participants' initial levels of suicidal ideation at baseline, $\left(\operatorname{Var}\left(v_{0 j}\right)=1.03, \chi^{2}(1)=4.82, p<.001\right)$. Participants with more insomnia symptoms $(t(212)=2.63, p=.009)$, and hopelessness $(t(214)=5.47, p<.001)$, had higher suicidal ideation (all $p$ 's $>.05$ for the other predictors).

On average, individuals' suicidal ideation decreased over time, with an estimated decrease of -0.60 points per year, $(t(309)=-6.89, p<.001)$. This decrease decelerated over time (i.e., the participants experienced less decline with increasing time), by an estimated 0.04 points per year, $(t(347)=8.84, p<.001)$. Of the 230 people who reported suicidal ideation at baseline, $33 \%$ also reported ideation at the 2 -year follow-up, with $31 \%, 26 \%$ and $23 \%$ reporting ideation at the 4-, 6- and 9-year follow-ups, respectively. Of those who continued to report ideation after baseline $(n=96), 16 \%$ reported ideation consistently across all assessment points.

There was significant variation in participants' course of suicidal ideation over time, (Var $\left.\left(v_{1 j}\right)=0.02, \chi^{2}(1)=2.76, p=.006\right)$. Those with more BPD traits $(t(194)=2.99, p=.003)$ experienced less decline in suicidal ideation over time, whereas those with more hopelessness 
experienced more decline over time $(t(200)=-4.24, p<.001)$ (all $p$ 's $>.05$ for other predictors). Older participants also had less decline in suicidal ideation over time $(t(198)=2.24, p=.026)$; however, the effect of age was no longer significant after correcting for multiple comparisons.

Figure 3 presents the average suicidal ideation course trajectories for a) different age groups, b) individuals with/without clinically significant insomnia (WHI-IRS $\geq 9$ ), c) with high/low hopelessness (i.e., above or below the group mean, LEIDS $_{H O P} \geq 10$ ), and d) with/without potential BPD (PSQ-4 $\mathrm{BPD} \geq 5$ ).

$<$ Table 2 \& Figure 3>

\section{Predictors of persistent suicidal ideation}

We had data on 195 participants who reported either persistent suicidal ideation (i.e., present at both 6- and 9-year follow-ups, $\mathrm{n}=55$ ) or non-persistent suicidal ideation (i.e., present at either 6- or 9-year follow-up, $\mathrm{n}=140$; for participant flow see Figure 1).

The logistic regression results are presented in Table 3 . There was a significant effect of insomnia symptoms (Wald's $\chi^{2}(1)=5.14, p=.023$ ), hopelessness (Wald's $\chi^{2}(1)=8.89, p=$ .003 ) and use of other antidepressants (Wald's $\chi^{2}(1)=4.41, p=.036$ ) on persistent suicidal ideation. The model explained $34 \%$ of the variance in persistent suicidal ideation, correctly classifying $79 \%$ of the cases, with a sensitivity of $49 \%$ and specificity of $91 \%\left(\chi^{2}(25)=53.09\right.$, $p=.001)$.

$<$ Table 3>

\section{Mediation analysis (Post-hoc)}

The logistic regression results on persistent suicidal ideation showed two significant predictors: insomnia symptoms and hopelessness. On the basis of prior literature arguing that hopelessness might be a mediating factor linking insomnia symptoms with suicidal ideation (Mc Call \& Black, 2013), we ran a post-hoc mediation analysis with insomnia symptoms (mean of baseline and 2-year follow-up) as the predictor, hopelessness (mean of 2- and 4-year followup) as the mediator, and persistent suicidal ideation (6- and 9-year follow-up) as the outcome. Because 'use of other antidepressants' was significant in the previous analysis, we included it as a covariate.

The total effect of insomnia symptoms on persistent suicidal ideation was significant ( $b$ $=0.113, S E=0.037,95 \%$ CI $[0.040,0.186])$ (Figure S1a). More severe insomnia symptoms 
also predicted more hopelessness ( $b=0.292, S E=0.064,95 \%$ CI $[0.166,0.419])$, and more hopelessness in turn predicted persistent suicidal ideation $(b=0.190, S E=0.045,95 \% \mathrm{CI}$ $[0.102,0.279])$. After accounting for hopelessness, the effect of insomnia symptoms on persistent suicidal ideation (i.e., the direct effect) was no longer significant ( $b=0.071, S E=$ $0.041,95 \%$ CI $[-0.009,0.152]$ ) (Figure S1b). However, the indirect effect of insomnia symptoms through hopelessness was significant $(b=0.056, S E=.019,95 \% \mathrm{CI}[0.026,0.100])$. Hopelessness accounted for $49.6 \%$ of the effect of insomnia symptoms on persistent suicidal ideation.

\section{Discussion}

Our aim was to assess the course of suicidal ideation and to identify predictors of its persistence. In a growth model analysis, those with more severe insomnia symptoms and hopelessness reactivity had higher initial levels of suicidal ideation. Overall, suicidal ideation decreased over time, but those with more BPD traits experienced less decrease and those with more hopelessness reactivity experienced more decrease over time. In a logistic regression analysis, insomnia symptoms and hopelessness reactivity predicted persistence of suicidal ideation. Hopelessness reactivity mediated the effect of insomnia symptoms on persistent ideation. In summary, hopelessness reactivity and insomnia were associated with both aspects of suicidal ideation - current level and chronicity.

Our results are mostly in line with prior literature. Insomnia symptoms have been associated with suicidal ideation both cross-sectionally and longitudinally (Bernert et al., 2005; Ribeiro et al., 2012). Over 90\% of suicide attempters report sleep disturbances (Hall et al., 1999), and short sleep duration has been associated with suicidal ideation in the general population as well (Goodwin \& Marusic, 2008). A recent study found that insomnia symptoms predicted increases in suicidal ideation among young adults at risk of suicide (Bernert et al., 2017). We found that insomnia symptoms predicted having (or developing) persistent suicidal ideation. However, insomnia symptoms assessed at a single time point (i.e., at baseline) did not emerge as a significant predictor (in interaction with time) in our growth model analysis. In our persistence analysis we measured insomnia symptoms over a longer period of time (i.e., using the mean of the first three assessment time points) and this probably provided a more reliable index of chronic insomnia symptom severity (although the WHI-IRS only assesses the presence of insomnia symptoms in the past month).

Many theories have been proposed to explain the insomnia-suicidal ideation link. Biological explanations have focused on the neurotransmitter serotonin, which is important for 
the initiation and maintenance of sleep (Monti, 2011), while sleep deprivation can lead to alterations in the serotonergic system (Eimenhorst et al., 2012). Likewise, abnormalities in serotonin function have been observed in suicide victims (Chatzittofis et al., 2013). Chronic sleep deprivation has also been shown to be detrimental to cognitive functioning, leading to impaired decision making (Noh et al., 2012). Consequently, for insomniacs suicide may present as the only tangible solution to their problems (McCall \& Black, 2013). Hopelessness is also, by definition, associated with a perceived lack of options. Hence, lack of sleep may worsen any hopelessness the individual is experiencing, therefore conferring additional risk. Although a previous study of (predominantly male) young adults in the military did not find hopelessness to mediate the relationship between insomnia symptoms and prospective (one month) suicidal ideation (Ribeiro et al., 2012), we observed a significant mediating effect of hopelessness; longer-term sleep disturbance may be required to lead to increased hopelessness. It appears that insomnia symptoms in itself may not directly increase the risk of persistent suicidal ideation, but that insomnia symptoms can lead to more hopelessness, which in turn leads to the persistence of suicidal ideation.

The role of hopelessness reactivity was also highlighted in our previous cross-sectional NESDA study: individuals with remitted depression and a history of suicidal ideation reported more hopelessness reactivity than individuals without past suicidal ideation (Antypa et al., 2010). Hopelessness has also been found to longitudinally predict suicidal ideation (Kuo et al., 2004; Zhang et al., 2011) and suicide (Beck et al., 1985). We replicated the finding that hopelessness predicted the persistence of suicidal ideation over time (Zhang et al., 2011). In our growth model analysis, however, hopelessness reactivity was also associated with the long-term course of suicidal ideation, but was associated with more decline in suicidal ideation over time. It might be expected that while risk factors such as insomnia are more temporally stable, hopelessness reactivity is more variable over time. Hopelessness reactivity is the tendency to respond with hopelessness to states of mild sadness; this is difficult to assess in people who experience more than mild states of sadness. Hence, the employed scale (LEIDS) may assess hopelessness in people who are depressed and hopelessness reactivity (a more trait-like feature) in people who are no longer depressed. This may explain this somewhat contradictory finding. Dropout of participants with the worst disease course (i.e., those who experienced increasing symptoms) may also have influenced our results, in line with the observation that those with a history of a past suicide attempt had more missing data. It may also partly explain the general trend of decreasing suicidal ideation over time in our sample, although similar trajectories have previously been reported (Goldston et al., 2016; Handley et al., 2013; Myers et al., 1991). Our 
finding that the majority of those who reported suicidal ideation at baseline did not continue to report ideation at the 2-year follow-up is also consistent with the 'Fluid Vulnerability Theory', which states that suicidal crises are often time-limited and suicide risk fluctuates over time (Bryan \& Rudd, 2016). We also note that the mean suicidal ideation in our sample was low and the scores non-normally distributed, with a positive skew. Therefore, while most participants experienced decreases in suicidal ideation over time, they had only mild suicidal ideation to begin with.

We also found that participants with comorbid BPD traits experienced less decline in suicidal ideation over time. It is well established that chronic suicidal ideation is a central feature of BPD (for reviews see Black et al., 2004; Paris, 2002). A previous NESDA study found comorbid BPD traits to be associated with recurrent suicide attempts (Stringer et al., 2013). BPD traits are also associated with suicide attempts and ideation among mood disorder patients (Aaltonen et al., 2017). Our results add to these findings by demonstrating that individuals with more BPD traits also exhibit a worse course of suicidal ideation.

Loneliness, negative life events, and history of childhood trauma were not associated with either the course or persistence of suicidal ideation. Loneliness has previously been associated with increased odds of suicidal ideation cross-sectionally (Stravynski \& Boyer, 2001), and thwarted belongingness was found to mediate the effect of insomnia on suicidal ideation (Chu et al., 2016). However, previous longitudinal studies have failed to demonstrate loneliness to predict suicide (Lasgaard et al., 2011; Koivumaa-Honkanen et al., 2001). Findings on the relationship between negative life-events and suicide risk are also inconsistent (Cavanagh et al., 1999; Hall et al., 1999). Finally, we did not replicate the finding that individuals with a history of childhood trauma are at increased risk of suicide ideation later in life (Almeida, 2012; Brown et al., 1999). The effects of childhood trauma have been shown to be strongest for those with a history of emotional and sexual abuse (Brown et al., 1999; de Araújo \& Lara, 2016), whereas neglect appears to be less strongly associated with subsequent suicidal ideation and behavior (Norman et al., 2012). In our sample, experiences of neglect were more prevalent than those of abuse.

Some additional observations can be made. Although a past suicide attempt is generally considered to be the strongest predictor of subsequent suicidal ideation and behavior (Hawton et al., 2013), it did not emerge as a significant predictor in our analyses. This could be due to unreliable reporting of suicidal behavior in the sample (Eikelenboom et al., 2014), or due to a greater dropout among those with a history of attempt. It has also been demonstrated that the risk conferred by a previous attempt decreases substantially over time (Chu et al., 2015). 
Further, depressive/anxiety diagnoses/comorbidity were not associated with the course or persistence of suicidal ideation. Depressive symptoms previously distinguished between those with persistent and non-persistent suicidal ideation (Wilcox et al., 2010), and we also first observed an effect of symptom severity (which includes a suicidal ideation item): those with more severe depressive symptoms had increased odds of persistent suicidal ideation. However, this effect was no longer significant after the inclusion of insomnia symptoms and hopelessness reactivity, which emerged as significant predictors of persistence. This is contrary to prior findings of depression mediating the effect of insomnia symptoms on suicidal ideation (Allan et al., 2017; Bryan et al., 2015). Further, although SSRIs have sometimes been associated with increased suicidal risk (especially among children and adolescents, see e.g., Gibbons et al., 2007), we observed that other types of antidepressants predicted the persistence of suicidal ideation over time. This association may be explained by increased use of such medications among those with more treatment-resistant depression. Finally, we observed that older participants experience less decline of suicidal ideation over time, in line with reports that suicide rates generally increase with age (Hawton \& van Heeringen, 2009; WHO, 2014).

The present study has some limitations. First, the subsample of participants used for our analyses was selective, as we limited it to those participants who reported suicidal ideation at baseline and who had sufficient available data to be included in the analyses. Further, suicidal ideation severity was positively skewed (i.e., most participants only reported mild suicidal ideation). Dropouts had a worse clinical profile and might also have had a worse disease course, making our sample at the follow-ups biased towards less severe individuals. Second, as the presence of psychosis was an exclusion criteria for participation in the NESDA, we were unable to assess for its potential effects; future research should explore how other comorbidities, such as psychotic symptoms and substance abuse, influence the course of suicidal ideation. Third, we defined 'persistent' suicidal ideation as reporting suicidal ideation at two successive time points (6- and 9-years) in order to establish a non-overlapping timeline between the outcome and predictors (derived from baseline, 2- and 4-years); other categorizations of persistence may produce different findings. Fourth, our study constitutes an exploratory study, and we only corrected for multiple comparisons in our growth model (course) analysis, where we ran multiple successive preliminary models to choose the variables for our final model. Future research should further confirm our findings. Finally, our hopelessness measure (LEIDS hopelessness/suicidal reactivity subscale) has some overlap with the outcome (suicidal ideation), and when repeating the logistic regression analysis using only the hopelessnessreactivity items specifically, hopelessness was no longer significant (see supplement). Hence 
our findings of hopelessness in the persistence analysis may be partly influenced by a predisposition to suicidal ideation rather than hopelessness in general.

The present study also has distinct strengths. We used a long follow-up period and took into account a wide range of sociodemographic and clinical factors, which were also assessed longitudinally. This is important in explaining a complex phenomenon such as suicidal ideation, in which multiple chronic risk factors are known to be involved (Franklin et al., 2017; Hawton \& van Heeringen, 2009; Oquendo et al., 2006).

Clinical implications of our results signal toward the benefit of screening for sleep disturbances and hopelessness reactivity among suicidal individuals, which may help identify those at risk of chronic suicidal ideation. Sleep interventions may be insufficiently used in the treatment of suicidal ideation (Pigeon \& Caine, 2010). Many risk factors for suicide are impossible to change (such as age, gender and ethnicity), but these disturbances - insomnia symptoms and hopelessness - are treatable (Antypa et al., 2010; McCall \& Black, 2013). 


\section{References}

Aaltonen, K.I., Rosenström, T., Baryshnikov, I., Karpov, B., Melartin, T., Suominen, K., Heikkinen, M., Näätänen, P., Koivisto, M., Joffe, G., Isometsä, E., 2017. Mediating role of borderline personality traits in the effects of childhood maltreatment on suicidal behaviour among mood disorder patients. Eur. Psychiat. 44, 53-60.

Allan, N.P., Conner, K.R., Pigeon, W.R., Gros, D.F., Salami, T.K., Stecker, T., 2017. Insomnia and suicidal ideation and behaviors in former and current US service members: Does depression mediate the relation? Psychiatry Res. 252, 296-302.

Almeida, O.P., Draper, B., Snowdon, J., Lautenschlager, N.T., Pirkis, J., Byrne, G., Sim, M., Stocks, N., Flicker, L., Pfaff, J.J., 2012. Factors associated with suicidal thoughts in a large community study of older adults. Br. J. Psychiatry 201, 466-472.

Anestis, M.D., Soberay, K.A., Gutierrez, P.M., Hernández, T.D., Joiner, T.E., 2014. Reconsidering the link between impulsivity and suicidal behavior. Pers. Soc. Psychol. Rev. 18 (4), 366-386.

Antypa, N., Antonioli, M., Seretti, A., 2013. Clinical, psychological and environmental predictors of prospective suicide events in patients with bipolar disorder. J. Psychiatr. Res. 47 (11), 1800-1808.

Antypa, N., van der Does, A.J.W., Penninx, B.W.J.H., 2010. Cognitive reactivity: investigation of a potentially treatable marker of suicide risk in depression. J. Affect. Disord. 122, 4652 .

Beautrais, A.L., Joyce, P.R., Mulder, R.T., Fergusson, D.M., Deavoll, B.J., Nightingale, S.K., 1996. Prevalence and comorbidity of mental disorders in persons making serious suicide attempts: a case-control study. Am. J. Psychiatry 153, 1009-1014.

Beck, A.T., Steer, R.A. Kovacs, M., Garrison, B., 1985. Hopelessness and eventual suicide: a 10-year prospective study of patients hospitalized with suicidal ideation. Am. J. Psychiatry 142 (5), 559-563.

Beck, A.T., Kovacs, M., Weissman, A., 1979. Assessment of suicidal ideation: the Scale for Suicidal Ideation. J. Consult. Clin. Psychol. 47 (2), 343-352.

Bernert, R.A., Hom, M.A., Iwata, N.G., Joiner, T.E., 2017. Objectively assessed sleep variability as an acute warning sign of suicidal ideation in a longitudinal evaluation of young adults at high suicide risk. J. Clin. Psychiatry 78 (6), 678-687.

Bernert, R.A., Joiner, T.E., Cukrowicz, K.C., Schmidt, N.B., Krakow, B., 2005. Suicidality and sleep disturbances. Sleep 28 (9), 1135-1141. 
Bernstein, D.P., Fink, L., 1998. Childhood Trauma Questionnaire: a retrospective self-report manual. San Antonio, Texas: The Psychological Corporation.

Black, D. W., Blum, N., Pfohl, B., Hale, N., 2004. Suicidal behavior in borderline personality disorder: prevalence, risk factors, prediction, and prevention. J. Pers. Disord. 18 (3), 226-239.

Borges, G., Angst, J., Nock, M.K., Ruscio, A.M., Kessler, R.C., 2008. Risk factors for the incidence and persistence of suicide-related outcomes: a 10-year follow-up study using the National Comorbidity Survey. J. Affect. Disord. 105, 25-33.

Bostwick, J.M., Pankratz, V.S., 2000. Affective disorders and suicide risk: a reexamination. Am. J. Psychiatry 157, 1925-1932.

Brodsky, B.S., Oquendo, M., Ellis, S.P., Haas, G.L., Malone, K.M., Mann, J.J., 2001. The relationship of childhood abuse to impulsivity and suicidal behavior in adults with major depression. Am. J. Psychiatry 158, 1871-1877.

Brown, J., Cohen, P., Johnson, J.G., Smailes, E.M., 1999. Childhood abuse and neglect: specificity of effects on adolescent and young adult depression and suicidality. J. Am. Acad. Child Adolesc. Psychiatry 38 (12), 1490-1496.

Brugha, T., Bebbington, P., Tennant, C., Hurry, J., 1985. The List of Threatening Experiences: a subset of 12 life event categories with considerable long-term contextual threat. Psychol. Med. 15, 189-194.

Bryan, C.J., Gonzales, J., Rudd, M.D., Bryan, A.O., Clemans, T.A., Ray-Sannerud, B., Wertenberger, E., Leeson, B., Heron, E.A., Morrow, C.E., 2015. Depression mediates the relation of insomnia severity with suicide risk in three clinical samples of US military personnel. Depress. Anxiety 32 (9), 647-655.

Bryan, C.J., Rudd, M.D., 2016. The importance of temporal dynamics in the transition from suicidal thought to behavior. Clin. Psychol. Sci. Pr. 23 (1), 21-25.

Busch, K.A., Fawcett, J., Jacobs, D.G., 2003. Clinical correlates of inpatient suicide. J. Clin. Psychiatry 64, 14-19.

Cavanagh, J.T.O., Carson, A.J., Sharpe, M., Lawrie, S.M., 2003. Psychological autopsy studies of suicide: a systematic review. Psychol. Med. 33, 395-405.

Cavanagh, J.T.O., Owens, D.G.C., Johnstone, E.C., 1999. Life events in suicide and undetermined death in South-East Scotland: a case-control study using the method of psychological autopsy. Soc. Psychiatry Psychiatr. Epidemiol. 34 (12), 645-650. 
Chatzittofis, A., Nordström, P., Hellström, C., Arver, S., Åsberg, M., Jokinen, J., 2013. CSF 5HIAA, cortisol and DHEAS levels in suicide attempters. Eur. Neuropsychopharmacol. 23 (10), 1280-1287.

Chu, C., Klein, K.N., Buchman-Achmitt, J.M., Hom., M.A., Hagan, C.R., Joiner, T.E., 2015. Routinized assessment of suicide risk in clinical practice: An empirically informed update. J. Clin. Psychol. 71 (12), 1186-1200.

Daniels, M.H., Zhao, Y.D., 2003. Modelling the random effects covariance matric in longitudinal data. Stat. Med. 22 (10), 1631-1647.

de Araújo, R.M.F., Lara, D.R., 2016. More than words: the association of childhood emotional abuse and suicidal behavior. Eur. Psychiat. 37, 14-21.

de Jong-Gierveld, J., Kamphuis, F., 1985. The development of a Rasch-type loneliness scale. Appl. Psychol. Meas. 9 (3), 289-299.

Duberstein, P.R., Conwell, Y., 1997. Personality disorders and completed suicide: a methodological and conceptual review. Clin. Psychol. Sci. Pract. 4 (4), 359-376.

Eikelenboom, M., Smit, J.H., Beekman, A.T.F., Kerkhof, A.J.F.M., Penninx, B.W.J.H., 2014. Reporting suicide attempts: consistency and its determinants in a large mental health survey. Int. J. Methods Psychiatr. Res. 23 (2), 257-266.

Eimenhorst, D., Kroll, T., Matusch, A., Bauer, A., 2012. Sleep deprivation increases cerebral serotonin 2A receptor binding in humans. Sleep 35 (12), 1615-1623.

Fergusson, D.M., Woodward, L.J., Horwood, L.J., 2000. Risk factors and life processes associated with the onset of suicidal behavior during adolescence and early adulthood. Psychol. Med. 30, 23-39.

Forsell, Y., 2000. Death wish in the very elderly: data from a 3-year follow-up study. Acta Psychiatr. Scand. 83, 115-120.

Foster, T., Gillespie, K., McClelland, R., Patterson, C., 1999. Risk factors for suicide independent of DSM-III-R Axis I disorder. Br. J. Psychiatry 175, 175-179.

Franklin, J.C., Ribeiro, J.D., Fox, K.R., Bentley, K.H., Kleiman, E.M., Huang, X., Musacchio, K.M., Jaroszewski, A.C., Chang, B.P., Nock, M.K., 2017. Risk factors for suicidal thoughts and behaviors: a meta-analysis of 50 years of research. Psychol. Bull. 143 (2), $187-232$.

Gibbons, R.D., Brown, C.H., Hur, K., Marcus, S.M., Bhaurnik, D.K., Erkens, J.A., Herings, R.M.C., Mann, J.J., 2007. Early evidence on the effects of regulators' suicidality warnings on SSRI prescriptions and suicide in children and adolescents. Am. J. Psychiatry $164(9), 1356-1363$. 
Goldston, D.B., Erkanli, A., Daniel, S.S., Heilbron, N., Weller, B., Doyle, O., 2016. Developmental trajectories of suicidal thoughts and behaviors from adolescence through adulthood. J. Am. Acad. Child Adolesc. Psychiatry 55 (5), 400-407.

Goodwin, R.D., Marusic, A., 2008. Association between short sleep and suicidal ideation and suicide attempt among adults in the general population. Sleep 31 (8), 1097-1101.

Hall, R.C.W., Platt, D.E., Hall, R.C.W., 1999. Suicide risk assessment: a review of risk factors for suicide in 100 patients who made severe suicide attempts. Psychosomatics 40, 1827.

Handley, T.E., Attia, J.R., Inder, K.J., Kay-Lambkin, F.J., Barker, D., LEwin, T.J., Kelly, B.J., 2013. Longitudinal course and predictors of suicidal ideation in a rural community sample. Aust. N. Z. J. Psychiatry 47 (11), 1032-1040.

Hawton, K., Casañas i Comabella, C., Haw, C., Saunders, K., 2013. Risk factors for suicide in individuals with depression: a systematic review. J. Affect. Disord. 147, 17-28.

Hawton, K., van Heeringen, K., 2009. Suicide. Lancet 373, 1372-1381.

Hayes, A.F., 2012. PROCESS: a versatile computational tool for observed variable mediation, moderation, and conditional process modeling. http://www.afhayes.com/public/process2012.pdf (accessed 20 May 2018).

Heck, R.H., Thomas, S.L., Tabata, L.N., 2014. Multilevel and longitudinal modeling with IBM SPSS. Routledge, New York.

Henriksson, M.M., Aro, H.M., Marttunen, M.J., Heikkinen, M.E., Isometsä, E.T., Kuoppasalmi, K.I., Lönnqvist, J.K., 1993. Mental disorders and comorbidity in suicide. Am. J. Psychiatry 150, 935-940.

Hyler, S.E., Skodol, A.E., Kellman, H.D., Oldham, J.M., Rosnick, L., 1990. Validity of the Personality Diagnostic Questionnaire - Revised: comparison with two structured interviews. Am. J. Psychiatry 147, 1043-1048.

Kessler, R.C., Borges, G., Walters, E.E., 1999. Prevalence of and risk factors for lifetime suicide attempts in the National Comorbidity Survey. Arch. Gen. Psychiatry 56 (7), 617626.

Kooistra, L.C., Wiersma, J.E., Ruwaards, J.J., Riper, H., Penninx, B.W.J.H., van Oppen, P., 2018. Six-year healthcare trajectories of adults with anxiety and depressive disorders: determinants of transition to specialized mental healthcare. J. Affect. Disord. 241, 226234. 
Koivumaa-Honkanen, H., Honkanen, R., Viinamäki, H., Heikkilä, K., Kaprio, J., Koskenvuo, M., 2002. Life satisfaction and suicide: a 20-year follow-up study. Am. J. Psychiatry $158(3), 433-439$.

Kuo, W.H., Gallo, J.J., Eaton, W.W., 2004. Hopelessness, depression, substance disorder and suicidality: a 13-year community-based study. Soc. Psychiatry Psychiatr. Epidemiol. 39 (6), 487-501.

Lamers, F., Beekman, A.T.F., van Hemert, A.M., Schoevers, R.A., Penninx, B.W.J.H., 2016. Six-year longitudinal course and outcomes of subtypes of depression. Br. J. Psychiatry $208,62-68$.

Lamers, F., Hoogendoorn, A.W., Smit, J.H., van Dyck, R., Zitman, F.G., Nole, W.A., Penninx, B.W., 2012. Sociodemographic and psychiatric determinants of attrition in the Netherlands Study of Depression and Anxiety. Compr. Psychiatry 53, 63-70.

Lasgaard, M., Goossens, L., Elklit, A., 2011. Loneliness, depressive symptomatology, and suicide ideation in adolescence: cross-sectional and longitudinal analyses. J. Abnorm. Child Psych. 39, 137-150.

Levine, D.W., Kripke, D.F., Kaplan, R.A., Lewis, M.A., Naughton, M.J., Bowen, D.J., Shumaker, S.A., 2003. Reliability and validity of the Women's Health Initiative Insomnia Rating Scale. Psychol. Assess. 15 (2), 137-148.

McCall, W.V., Black, C.G., 2013. The link between suicide and insomnia: theoretical mechanisms. Curr. Psychiat. Rep. 15, 389.

Minkoff, K., Bergman, E., Beck, B.T., Beck, R., 1973. Hopelessness, depression, and attempted suicide. Am. J. Psychiatry 130 (4), 455-459.

Monti, J., 2011. Serotonin control of sleep-wake behavior. Sleep Med. Rev. 15, 269-281.

Myers, K., McCauley, E., Calderon, R., Treder, R., 1991. The 3-year longitudinal course of suicidality and predictive factors for subsequent suicidality in youths with major depressive disorder. J. Am. Acad. Child Adolesc. Psychiatry 30 (5), 804-810.

Nock, M.K., Borges, G., Bromet, E.J., Alonso, J., Angermeyer, M., Beautrais, A., Bruffaerts, R., Chiu, W.T., de Girolamo, G., Gluzman, S., de Graaf, R., Gureje, O., Haro, J.M., Huang, Y., Karam, E., Kessler, R.C., Lepine, J.P., Levinson, D., Medina-Mora, E., Ono, Y., Posada-Villa, J., Williams, D., 2008. Cross-national prevalence and risk factors for suicidal ideation, plans and attempts. Br. J. Psychiatry 192, 98-105.

Noh, H.J., Joo, E.Y., Kim, S.T., Yoon, S.M., Koo, D.L., Kim, D., Lee, G.H., Hong, S.B., 2012. The relationship between hippocampal volume and cognition in patients with chronic primary insomnia. J. Clin. Neurol. 8 (2), 130-138. 
Norman, R.E., Byambaa, M., De, R., Butchart, A., Scott, J., Vos, T., 2012. The long-term health consequences of child physical abuse, emotional abuse, and neglect: a systematic review and meta-analysis. PLoS Med. 9 (11), e1001349.

O’Connor, R.C., Nock, M.K., 2014. The psychology of suicidal behavior. Lancet Psychiatry 1 (1), 73-85.

Oquendo, M.A., Currier, D., Mann, J.J., 2006. Prospective studies of suicidal behavior in major depressive and bipolar disorder: what is the evidence for predictive risk factors? Acta Psychiatr. Scand. 114, 151-158.

Paris, J., 2002. Chronic suicidality among patients with borderline personality disorder. Psychiatr. Serv. 53 (6), 738-742.

Penninx, B.W.J.H., Beekman, A.T.F., Smit, J.H., Fitman, F.G., Nolen, W.A., Spinhoven, P., Cuijpers, P., de Jong, P.J., van Marwijk, H.W.J., Assendelft, W.J.J., van der Meer, K., Verhaak, P., Wensing, M., de Graaf, R., Hoogendijk, W.J., Ormel, J., van Dyck, R., 2008. The Netherlands Study of Depression and Anxiety (NESDA): rationale, objectives and methods. Int. J. Methods Psychiatr. Res. 17 (3), 121-140.

Perlis, M.L., Grandner, M.A., Chakravorty, S., Bernert, R.A., Brown, G.K., Thase, M.E., 2016. Suicide and sleep: is it a bad thing to be awake when reasons sleep? Sleep Med. Rev. 29, 101-107.

Pigeon, W.R., Caine, E.D., 2010. Insomnia and the risk for suicide: does sleep medicine have interventions that can make a difference? Sleep Med. 11, 816-817.

Preacher, K.J., Hayes, A.F., 2004. SPSS and SAS procedures for estimating indirect effects in simple mediation models. Behav. Res. Methods Instrum. Comput. 36 (4), 717-731.

Ribeiro, J.D., Pease, J.L., Gutierrez, P.M., Silva, C., Bernert, R., Rudd, M.D., Joiner, T.E., 2012. Sleep problems outperform depression and hopelessness as cross-sectional and longitudinal predictors of suicidal ideation and behavior in young adults in the military. J. Affect. Disord. 136, 743-750.

Robins, L.N., Wing, J., Wittchen, H.U., Helzer, J.E., Babor, T.F., Burke, J., Farmer, A., Jablenski, A., Pickens, R., Regier, D.A., Sartorius, N., Towle, L.H., 1988. The Composite International Diagnostic Interview: an epidemiologic instrument suitable for use in conjunction with different diagnostic systems and in different cultures. Arch. Gen. Psychiatry 45 (12), 1069-1077.

Rossom, R.C., Coleman, K.J., Ahmedani, B.K., Beck, A., Johnson, E., Oliver, M., Simon, G.E., 2017. Suicidal ideation reported on the PHQ9 and risk of suicidal behavior across age groups. J. Affect. Disord. 215, 77-84. 
Rush, A.J., Giles, D.E., Schlesser, M.A., Fulton, C.L., Weissenburger, J., Burns, C., 1986. The Inventory of Depressive Symptomatology (IDS): preliminary findings. Psychiatry Res. $18,65-87$.

Rush, A.J., Gullion, C.M., Basco, M.R, Jarrett, R.B., Trivedi, M.H., 1996. The Inventory of Depressive Symptomatology (IDS): psychometric properties. Psychol. Med. 26, 477486.

Smith, J.M., Alloy, L.B., Abramson, L.Y., 2006. Cognitive vulnerability to depression, rumination, hopelessness and suicidal ideation: multiple pathways to self-injurious thinking. Suicide Life Threat. Behav. 36 (4), 443-454.

Solis, E., Antypa, N., Conijn, J.M., Kelderman, H., van der Does, W., 2017. Psychometric properties of the Leiden Index of Depression Sensitivity (LEIDS). Psychol. Assess. 29 (2), 158-171.

Stravynski, A., Boyer, R., 2001. Loneliness in relation to suicidal ideation and parasuicide: a population-wide study. Suicide Life Threat. Behav. 31 (1), 32-40.

Stringer, B., van Meijel, B., Eikelenboom, M., Koekkoek, B., Licht, C.M.M., Kerkhof, A.J.F.M., Penninx, B.W.J.H., Beekman, A.T.F., 2013. Recurrent suicide attempts in patients with depressive and anxiety disorders: the role of borderline personality traits. J. Affect. Disord. 151, 23-30.

Stroebe, M., Stroebe, W., Abakoumkin, G., 2005. The broken heart: suicidal ideation in bereavement. Am. J. Psychiatry 162, 2178-2180.

ten Have, M., de Graaf, R., van Dorsselaer, S., Verdurmen, J., van 't Land, H., Vollebergh, W., Beekman, A., 2009. Incidence and course of suicidal ideation and suicide attempts in the general population. Can. J. Psychiatry 54 (12), 825-833.

van der Does, W., 2002. Cognitive reactivity to sad mood: structure and validity of a new measure. Behav. Res. Ther. 40, 105-120.

Wilcox, H.C., Arria, A.M., Caldeira, K.M., Vincent, K.B., Pinchevsky, G.M., O’Grady, K.E., 2010. Prevalence and predictors of persistent suicide ideation, plans, and attempts during college. J. Affect. Disord. 127 (1-3), 287-94.

World Health Organization, 2018. Suicide Fact Sheet. Geneva: WHO. http://www.who.int/mediacentre/factsheets/fs398/en/ (accessed 31 January 2018).

World Health Organization, 2014. World Report on Violence and Health. Geneva: WHO.

World Health Organization, 1998. Composite International Diagnostic Interview (CIDI), version 2.1. Geneva: WHO. 
Wortzel, H.S., Homaifar, B., Matarazzo, B., Brenner, L.A., 2014. Therapeutic risk management of the suicidal patient: stratifying risk in terms of severity and temporality. J. Psychiatr. Pract. 20 (1), 63-67.

Yen, S., Shea, M. T., Sanislow, C. A., Grilo, C. M., Skodol, A. E., Gunderson, J. G., McGlashan, T.H., Zanarini, M.C., Morey, L. C., 2004. Borderline personality disorder criteria associated with prospectively observed suicidal behavior. Am. J. Psychiatry 161 (7), 1296-1298.

Yufit, R.I., Lester, D., 2005. Assessment, treatment, and prevention of suicidal behavior. Hoboken, New Jersey.

Zhang, Y., Law, C.K., Yip, P.S.F., 2011. Psychological factors associated with the incidence and persistence of suicidal ideation. J. Affect. Disord. 133, 584-590.

Zimmerman, M., Chelminski, I., Young, D., Dalrymple, K., Martinez, J., 2012. Does the presence of one feature of borderline personality disorder have clinical significance? Implications for dimensional ratings of personality disorders. J. Clin. Psychiatry 73 (1), $8-12$. 
Table 1.

Sample characteristics at baseline

$\begin{array}{ccccc}\begin{array}{c}\text { All } \\ (\mathbf{N}=\mathbf{2 1 3 0})\end{array} & \begin{array}{c}\text { Baseline Suicidal } \\ \text { ideators } \\ (\mathrm{n}=\mathbf{2 3 0}, \mathbf{1 1 \%})\end{array} & \begin{array}{c}\text { Non-suicidal } \\ (\mathrm{n}=\mathbf{1 9 0 0}, \mathbf{8 9} \%)\end{array} & \begin{array}{c}\text { Chi-square/ } \\ \text { t-test }\end{array} & \text { p-value } \\ & & & \\ \end{array}$

Sociodemographics

Gender, female (n, \%)

Age, years (m, sd)

Nationality, Dutch (n, \%)

Married/with partner (n, \%)

Children (n, \%)

Education, years (m, sd)

Currently working (n, \%)

Religious (n, \%)

Clinical characteristics

Diagnosis (n, \%)

Lifetime depression

Lifetime anxiety

Current depression

Dysthymia

Major depression

Current anxiety

GAD

Social phobia

Panic disorder (with/out agoraphobia)

Agoraphobia

Symptom severity (m, sd)

Any comorbidity

Comorbid depression and anxiety

Medication (n, \%)

SSRIs

Other antidepressants

Benzodiazepines

Hypnotics/sedatives

Suicidal ideation (m, sd)

Suicide attempt history (n, \%)

Borderline personality traits $(\mathrm{m}, \mathrm{sd})$

Clinical level (n, \%)

Insomnia (m, sd)

Clinical level (n, \%)

Hopelessness (m, sd)

Loneliness (m, sd)

Childhood trauma (m, sd)

Emotional abuse

Physical abuse

Sexual abuse

Emotional neglect

Physical neglect

Negative life events (m, sd)

$1430(67 \%)$
$42.4(13.1)$
$2090(98 \%)$
$1502(71 \%)$
$1168(55 \%)$
$12.5(3.2)$
$1308(61 \%)$
$793(37 \%)$

$153(67 \%)$

$41.4(12.0)$

223 (97\%)

$136(59 \%)$

$117(51 \%)$

$12.2(3.2)$

105 (46\%)

85 (37\%)

$1277(67 \%)$
$42.5(13.3)$
$1867(98 \%)$
$\mathbf{1 3 6 6}(\mathbf{7 2 \%})$
$1051(55 \%)$
$12.5(3.2)$
$\mathbf{1 2 0 3}(\mathbf{6 3 \% )}$
$708(37 \%)$

0.04

$1.30^{\mathrm{a}}$

1.90

16.08

1.64

$1.23^{\mathrm{a}}$

27.01

0.01

.834

.195

.168

$<.001$

.201

.220

$<.001$

.928

$1355(64 \%)$
$1191(56 \%)$
$785(37 \%)$
$185(9 \%)$
$712(33 \%)$
$843(40 \%)$
$276(13 \%)$
$439(21 \%)$
$421(20 \%)$
$123(6 \%)$
$19.9(13.7)$
$634(30 \%)$
$487(23 \%)$

$$
\begin{gathered}
222(97 \%) \\
192(84 \%) \\
189(82 \%) \\
70(30 \%) \\
181(79 \%) \\
166(72 \%) \\
76(33 \%) \\
109(47 \%) \\
84(37 \%) \\
17(7 \%) \\
36.8(11.8) \\
169(74 \%) \\
143(62 \%)
\end{gathered}
$$

$343(16 \%)$

$168(8 \%)$

$296(14 \%)$

$133(6 \%)$

$0.3(1.0)$

$272(13 \%)$

1.8 (1.9)

$221(10 \%)$

$8.0(5.0)$

$912(43 \%)$

$4.6(4.5)$

$4.2(3.7)$

40.3 (13.9)

$8.6(4.4)$

$5.9(2.6)$

$6.1(3.0)$

$12.3(5.1)$

$7.4(2.8)$

0.8 (1.1)
38 (17\%)

57 (25\%)

32 (14\%)

$2.5(1.8)$

78 (34\%)

$3.3(2.3)$

$68(30 \%)$

$11.4(5.4)$

$169(74 \%)$

$10.5(5.0)$

7.0 (3.4)

48.6 (16.9)

$11.2(5.6)$

$6.8(3.5)$

7.1 (4.2)

$15.2(5.2)$

8.4 (3.2)

$0.9(1.0)$
$67(29 \%)$

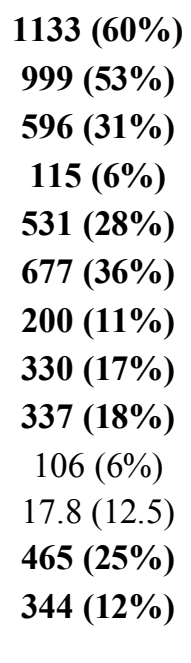

$276(15 \%)$

$130(7 \%)$

$239(13 \%)$

101 (5\%)

$194(10 \%)$

$1.6(1.8)$

$153(8 \%)$

7.6 (4.8)

743 (39\%)

3.8 (3.8)

3.9 (3.6)

39.2 (13.1)

8.3 (4.1)

$5.8(2.5)$

$6.0(2.8)$

$11.9(5.0)$

7.3 (2.7)

0.8 (1.0)
120.63

$<.001$

79.47

227.56

153.79

237.44

114.56

92.23

113.02

45.65

1.24

$-22.81^{\mathrm{a}}$

235.68

225.92

32.39

26.46

25.54

25.90

103.38

$-10.95^{\mathrm{a}}$

102.11

$-10.36^{\mathrm{a}}$

99.00

$-19.28^{\mathrm{a}}$

$-12.62^{\mathrm{a}}$

$-8.14^{\mathrm{a}}$

$-7.65^{\mathrm{a}}$

$-3.93^{\mathrm{a}}$

$-4.06^{\mathrm{a}}$

$-9.30^{\mathrm{a}}$

$-5.24^{\mathrm{a}}$

$-1.81^{\mathrm{a}}$

$<.001$

$<.001$

$<.001$

.266

$<.001$

$<.001$

$<.001$

$<.001$

$<.001$

$<.001$

$<.001$

$<.001$

$<.001$

$<.001$

$<.001$

$<.001$

$<.001$

$<.001$

$<.001$

$<.001$

$<.001$

$<.001$

$<.001$

$<.001$

.070

GAD Generalized anxiety disorder; Symptom severity as measured with the Inventory of depressive symptomatology; SSRIs Selective serotonin reuptake inhibitors; Other antidepressants incl. Tricyclic antidepressants, monoamine oxidase inhibitors and atypical

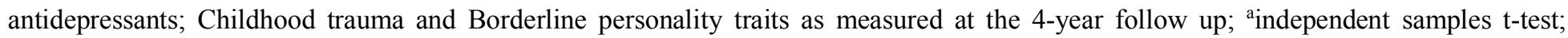
significant group differences are indicated in bold. 
Table 2 .

Linear mixed-effects growth model of suicidal ideation $(\mathrm{N}=\mathbf{2 3 0})$

\begin{tabular}{|c|c|c|c|c|c|}
\hline & $\mathrm{b}$ & $\mathrm{SE}$ & $95 \% \mathrm{CI}$ & Variance & Covariance \\
\hline Intercept & 1.978 & 0.467 & $1.058,2.897$ & 1.025 & -0.053 \\
\hline Time & -0.603 & 0.088 & $-0.776,-0.431$ & 0.018 & \\
\hline Quadratic time & 0.038 & 0.004 & $0.030,0.047$ & & \\
\hline \multicolumn{6}{|l|}{ Sociodemographics } \\
\hline \multicolumn{6}{|l|}{ Clinical characteristics } \\
\hline Symptom severity & -0.005 & 0.009 & $-0.023,0.014$ & & \\
\hline Hypnotics/sedatives & 0.344 & 0.279 & $-0.205,0.893$ & & \\
\hline Hopelessness $† \dagger$ & 0.116 & 0.021 & $0.074,0.157$ & & \\
\hline Borderline personality traits & 0.025 & 0.045 & $-0.064,0.115$ & & \\
\hline Emotional abuse & 0.028 & 0.020 & $-0.010,0.067$ & & \\
\hline Sexual abuse & 0.008 & 0.025 & $-0.041,0.058$ & & \\
\hline \multicolumn{6}{|l|}{ Interactions } \\
\hline Time X Age & 0.003 & 0.001 & $0.001,0.006$ & & \\
\hline Time X Employment status & 0.003 & 0.032 & $-0.059,0.065$ & & \\
\hline Time X Symptom severity & 0.002 & 0.002 & $-0.001,0.005$ & & \\
\hline Time X Emotional abuse & -0.003 & 0.003 & $-0.009,0.004$ & & \\
\hline Time X Sexual abuse & -0.008 & 0.004 & $-0.016,0.001$ & & \\
\hline
\end{tabular}

Benjamini-Hochberg critical value $\dagger \mathrm{p}<.01, \dagger \dagger \mathrm{p}<.005$; Variance and covariance of the intercept and slope (time); All continuous predictors have been grand-mean centered 
Table 3.

Logistic regression model on persistent $(n=55)$ versus non-persistent suicidal ideation $(n=140)($ Total $N=195)$

\begin{tabular}{|c|c|c|c|}
\hline & MODEL 1 & MODEL 2 & MODEL 3 \\
\hline & OR (CI 95\%) & OR (CI 95\%) & OR (CI 95\%) \\
\hline \multicolumn{4}{|l|}{ Sociodemographics } \\
\hline Gender & $0.73(0.38-1.42)$ & $0.86(0.42-1.78)$ & $0.91(0.37-2.12)$ \\
\hline Age & $1.00(0.97-1.03)$ & $1.00(0.97-1.03)$ & $0.99(0.96-1.03)$ \\
\hline Nationality & $0.77(0.08-7.35)$ & $0.55(0.48-6.36)$ & $0.40(0.02-7.46)$ \\
\hline Marital status & $0.81(0.41-1.63)$ & $0.89(0.41-1.92)$ & $0.91(0.37-2.23)$ \\
\hline Education & $1.03(0.93-1.14)$ & $1.06(0.95-1.19)$ & $1.12(0.98-1.28)$ \\
\hline Employment status & $1.92(1.00-3.69)$ & $1.72(0.84-3.54)$ & $1.50(0.68-3.33)$ \\
\hline \multicolumn{4}{|l|}{ Clinical characteristics ${ }^{a}$} \\
\hline Depression & & $0.99(0.28-3.47)$ & $1.00(0.27-3.76)$ \\
\hline Anxiety & & $0.37(0.11-1.26)$ & $0.25(0.06-1.08)$ \\
\hline Symptom severity ${ }^{b}$ & & $1.07(1.03-1.11) * * *$ & $1.01(0.96-1.06)$ \\
\hline Comorbidity & & $1.87(0.47-7.42)$ & $1.57(0.34-7.37)$ \\
\hline SSRI's & & $0.81(0.38-1.70)$ & $0.97(0.43-2.22)$ \\
\hline Other antidepressants & & $2.38(1.09-5.17) *$ & $2.66(1.07-6.63) *$ \\
\hline Benzodiazepines & & $0.59(0.23-1.50)$ & $0.64(0.23-1.78)$ \\
\hline Hypnotics/sedatives & & $0.78(0.27-2.24)$ & $0.62(0.20-1.92)$ \\
\hline Suicide attempt history & & $1.23(0.47-2.26)$ & $0.79(0.32-1.95)$ \\
\hline \multicolumn{4}{|l|}{ Predictors } \\
\hline Insomnia $^{b}$ & & & $1.14(1.02-1.28) *$ \\
\hline Hopelessness ${ }^{b}$ & & & $1.21(1.07-1.36) * *$ \\
\hline Loneliness ${ }^{b}$ & & & $1.03(0.88-1.20)$ \\
\hline Borderline personality traits & & & $1.11(0.89-1.38)$ \\
\hline Emotional abuse & & & $1.05(0.94-1.18)$ \\
\hline Physical abuse & & & $1.12(0.93-1.35)$ \\
\hline Sexual abuse & & & $0.94(0.84-1.07)$ \\
\hline Emotional neglect & & & $0.98(0.88-1.10)$ \\
\hline Physical neglect & & & $0.90(0.74-1.10)$ \\
\hline Negative life events ${ }^{c}$ & & & $0.95(0.84-1.07)$ \\
\hline
\end{tabular}

${ }^{*} \mathrm{p}<.05,{ }^{* *} \mathrm{p}<.01,{ }^{* * *} \mathrm{p}<.001 ;{ }^{a}$ Current depression/anxiety/comorbidity/medication use/suicide attempt history at Time A (dichotomous), ${ }^{b}$ Mean of Time A, ${ }^{c}$ Sum of Time A 


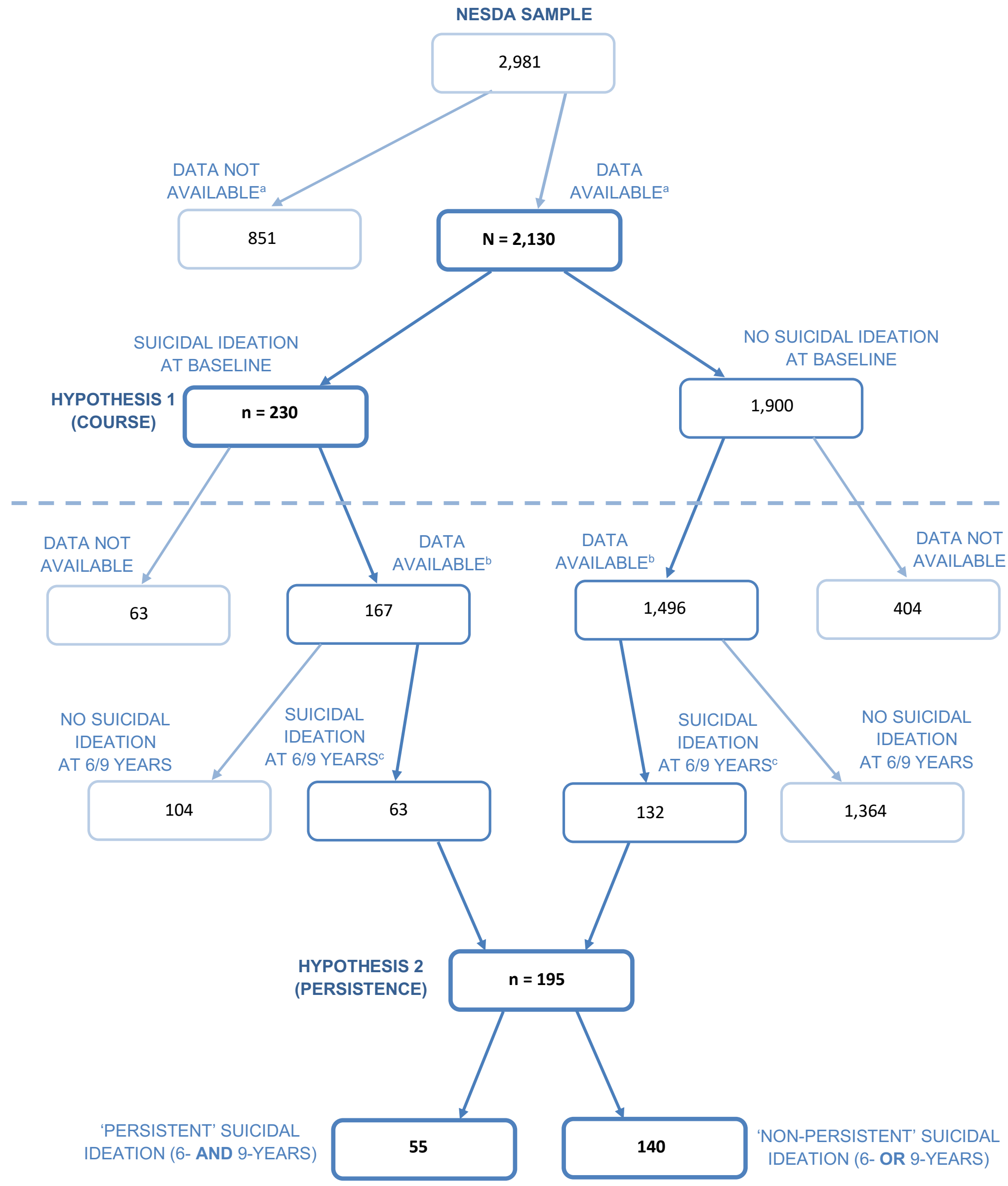

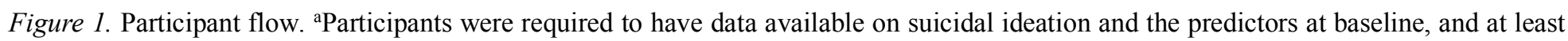

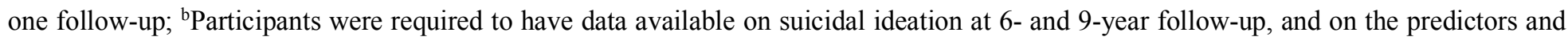
covariates at baseline, 2- and 4-year follow-up; 'Participants were required to have suicidal ideation (BSSI $>0$ ) at 6- and/or 9-year follow up. 
(a) 'Course' analyses

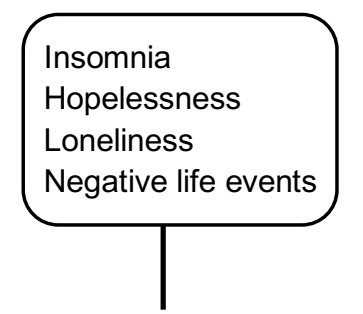

Borderline personality traits

Childhood trauma

Suicidal ideation ${ }^{1}$

Suicidal ideation ${ }^{1}$

Suicidal ideation ${ }^{1}$

Suicidal ideation ${ }^{1}$

Suicidal ideation ${ }^{1}$

(b) 'Persistence' analyses

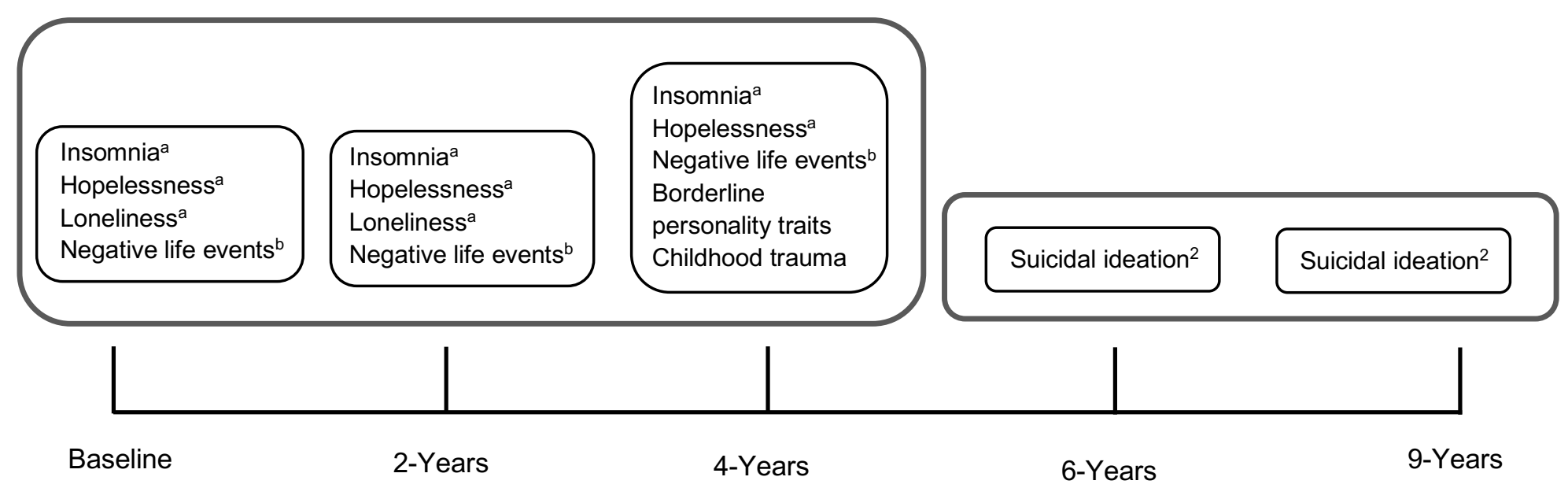

Figure 2. A schematic overview of the assessment time points for the outcome (suicidal ideation) and predictors in the (a) 'Course' analyses and (b) 'Persistence' analyses.

${ }^{1}$ Suicidal ideation sum score.

${ }^{2}$ Suicidal ideation present/absent.

${ }^{\mathrm{a}}$ Mean of Baseline, 2- and 4-year follow-up, ${ }^{\mathrm{b}} \mathrm{Sum}$ of Baseline, 2- and 4-year follow-up.

Note: Borderline personality traits and childhood trauma were only assessed at the 4-year follow-up. 
(a)

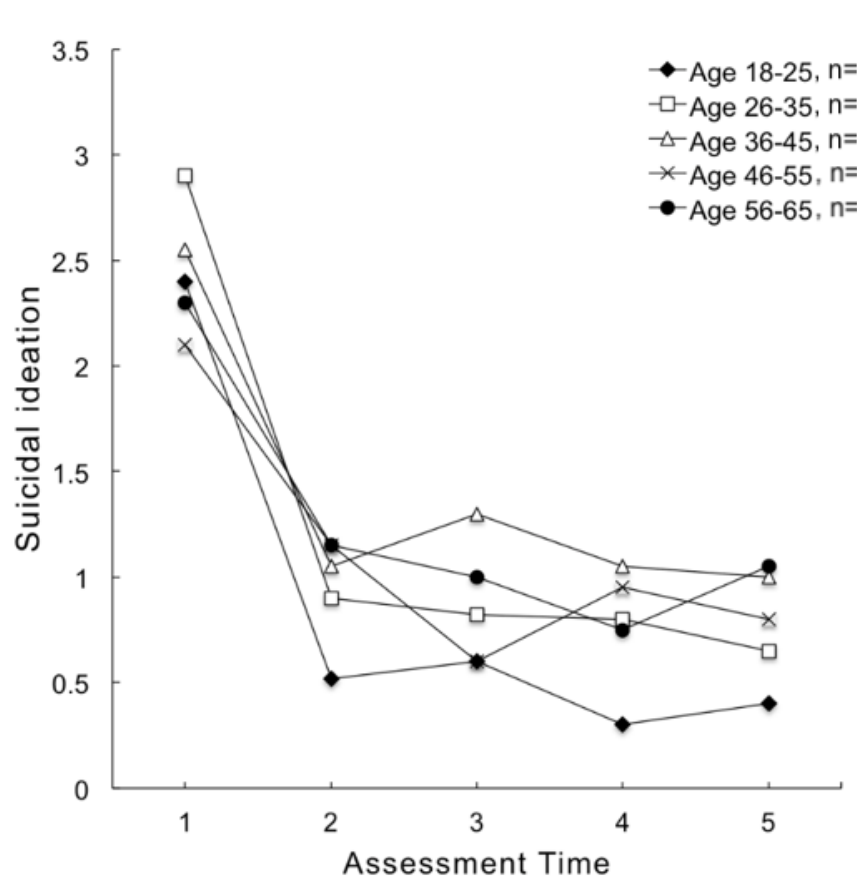

(c)

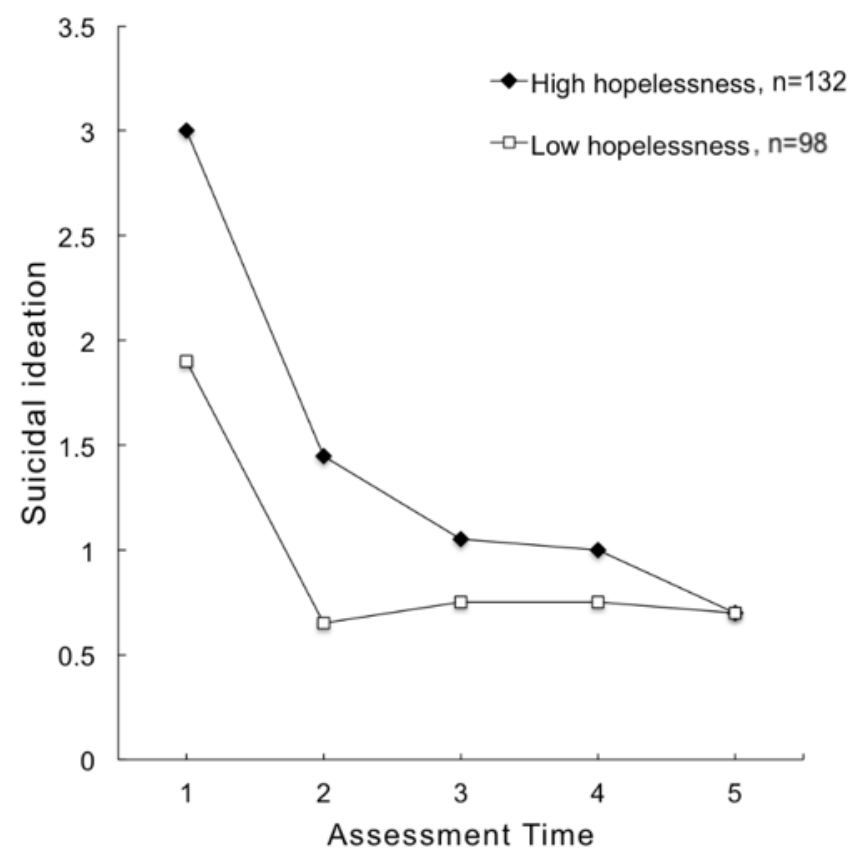

(b)

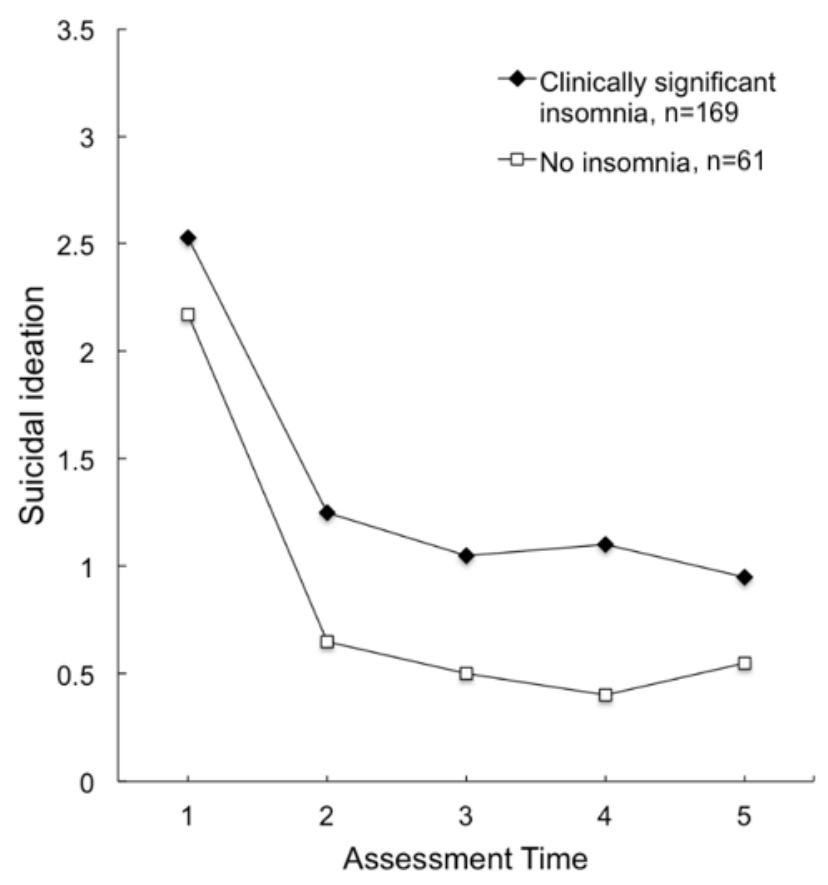

(d)

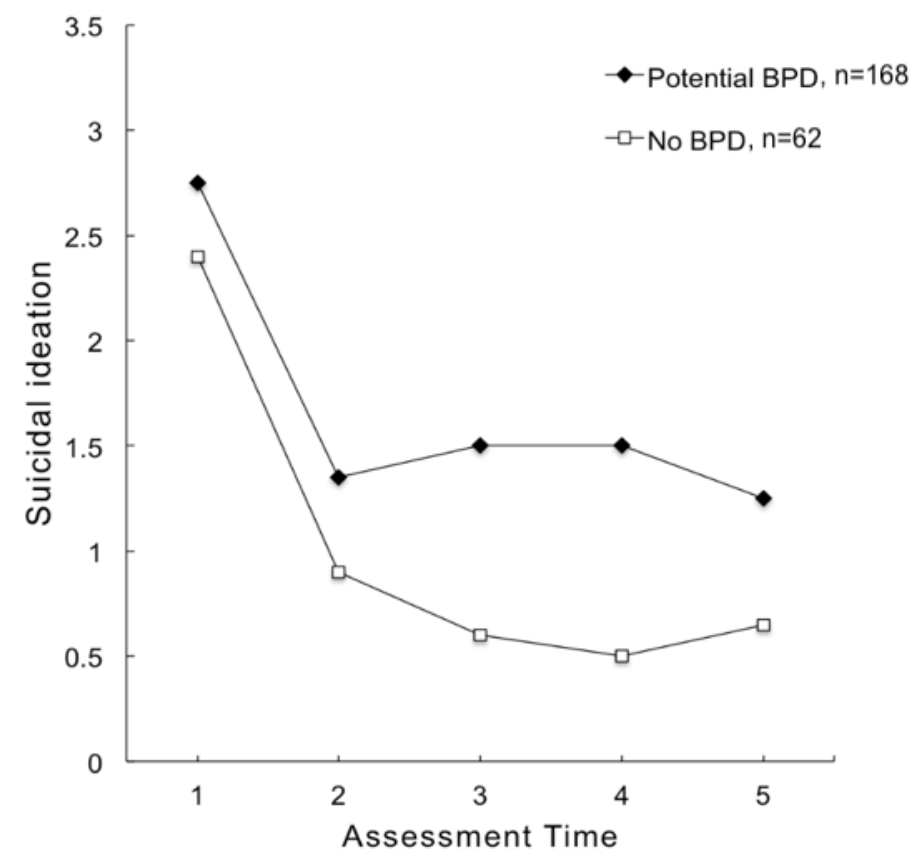

Figure 3. Average suicidal ideation course trajectories for different groups; BPD Borderline personality disorder, T1; Baseline, T2; 2-year, T3; 4-year, T4; 6-year, T5; 9-year follow-up. 